\title{
WOBKPLLBE SOLDIDNS
}

\section{Reducing Exposure to Lead and Noise at Outdoor Firing Ranges}

\section{Summary}

The National Institute for Occupational Safety and Health (NIOSH) recently published recommendations for reducing exposure to lead and noise at indoor firing ranges [NIOSH 2009]. However, workers and users of outdoor firing ranges may be exposed to similar hazards. This followup document examines exposures at these ranges and recommends steps to reduce such exposures.

\section{Description of Exposure}

\section{Affected Population}

According to the Bureau of Justice Statistics, more than 1.2 million Federal, State, and local law enforcement officers work in the United States [DOJ 2012, 2011]. These officers are required to train regularly in the use of firearms and may be exposed to hazardous levels of lead and noise if they train at outdoor ranges. In addition to law enforcement, NIOSH estimates that shooting ranges employ 40,000-60,000 workers, and that about $15 \%$ of the U.S. population, or 34.4 million people, participate in target shooting [NSSF 2010].

\section{Exposure Sources}

Several studies of outdoor firing ranges have shown that exposure to lead and noise can cause health problems, particularly among employees and instructors [NIOSH 2011; Tripathi et al. 1991; Goldberg et al. 1991]. Lead exposure occurs mainly through inhalation of lead dust, skin contact with lead from bullets, or ingestion (e.g., eating or drinking with contaminated hands) [NIOSH 2009]. Workers and shooters involved in shooting, cleaning operations, collecting casings, and handling spent bullets may also be exposed to lead.

\section{Indoor vs. Outdoor Ranges}

An estimated 9,000 non-military outdoor ranges exist in the United States, with millions of pounds of lead from bullets shot annually. Because outdoor ranges are typically built in an open area, lead and noise are more widely dispersed. Outdoor ranges need less cleaning and maintenance than indoor ranges. However, despite the natural ventilation of outdoor firing ranges, personal breathing zone lead levels can exceed the NIOSH recommended exposure limit (REL) and Occupational Safety and Health Administration (OSHA) permissible exposure limit (PEL) [Mancuso et al. 2008]. Some outdoor ranges have ballistic baffles overhead and concrete walls and structures on the sides. The air in these spaces can become stagnant and lead to increased exposures.

\section{Exposure Limits}

\section{Lead}

OSHA has established two different limits for airborne exposure to lead [29 CFR $1910.1025^{*}$. The action level for airborne lead exposure is 30 micrograms per cubic meter of air $\left(\mu \mathrm{g} / \mathrm{m}^{3}\right)$ as an 8 -hour time weighted average (TWA). The OSHA PEL for airborne exposure to lead is $50 \mu \mathrm{g} / \mathrm{m}^{3}$ as an 8-hour TWA. For workers exposed to airborne lead above the action level for more than 30 days per year, OSHA requires blood lead monitoring every 6 months. If an employee's blood lead level (BLL) exceeds $60 \mu \mathrm{g}$ lead/100 $\mathrm{g}$ of whole blood (or the average of the last 3 BLLs is greater than $50 \mu \mathrm{g}$ lead/100 g), the employee must be removed from further exposure until BLLs decline to $40 \mu \mathrm{g}$ lead/100 g or less.

The NIOSH REL for airborne lead is $50 \mu \mathrm{g} / \mathrm{m}^{3}$ as an 8 -hour TWA.

The U.S. Department of Health and Human Services recommends that BLLs among all adults be reduced to $<10 \mu \mathrm{g} / \mathrm{dL}$ [DHHS 2011].

\section{Noise}

For noise exposure, the OSHA PEL is 90 decibels, A-weighted (dBA), and the action level is $85 \mathrm{dBA}$ both as an 8-hour

*Code of Federal Regulations. See CFR in References.
DEPARTMENT OF HEALTH AND HUMAN SERVICES Centers for Disease Control and Prevention National Institute for Occupational Safety and Health

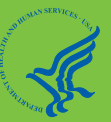

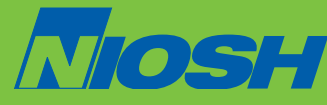


TWA using a 5-dB exchange rate [29 CFR 1910.95]. The OSHA occupational noise standard states that exposures to impulsive noise should not exceed $140 \mathrm{~dB}$ peak sound pressure level (SPL).

The NIOSH REL for noise (8-hour TWA) is $85 \mathrm{dBA}$ using a 3-dB exchange rate [NIOSH 1998]. NIOSH also recommends that peak SPL not exceed $140 \mathrm{~dB}$.

\section{NIOSH Investigations}

NIOSH conducted Health Hazard Evaluations that involved exposure to lead and noise to law enforcement officers and employees at outdoor firing ranges (Figure 1).

\section{Lead}

At a firing range in California, 16 personal breathing zone (PBZ) air samples and six surface wipe samples were collected for lead. The air samples did not exceed occupational exposure limits (REL or PEL) for lead. The highest lead exposure $\left(15 \mu \mathrm{g} / \mathrm{m}^{3}\right)$ was measured on an instructor at the range. Exposures can vary depending on weather conditions (particularly wind speed and direction) and the shooter's proximity to the gun smoke source. The highest levels of surface contamination were on the firearms. Lead was also found on outdoor picnic tables where employees ate. Colorimetric wipe tests identified lead on hands, but employees had good personal hygiene practices; no lead was found on hand wipes after hand washing [NIOSH 2011].

\section{Noise}

NIOSH evaluated the noise exposure of a SWAT team in Fort Collins, CO, during training exercises. Hearing was tested before and immediately after training sessions. Noise measurements were made of firearms and of the protection offered by customized hearing protectors. Most officers did not show any change in hearing after shooting, but the oldest group did show mild hearing loss at higher frequencies. Firearm noise was between 159 and $169 \mathrm{~dB}$, which was greater than the $140 \mathrm{~dB}$ peak limit for impulsive noise. Peak noise reductions from the ear plugs, ear muffs, and customized protectors were in the $30 \mathrm{~dB}$ range. Double hearing protection (plugs plus muffs) added 15-20 dB of additional protection [NIOSH 2003].

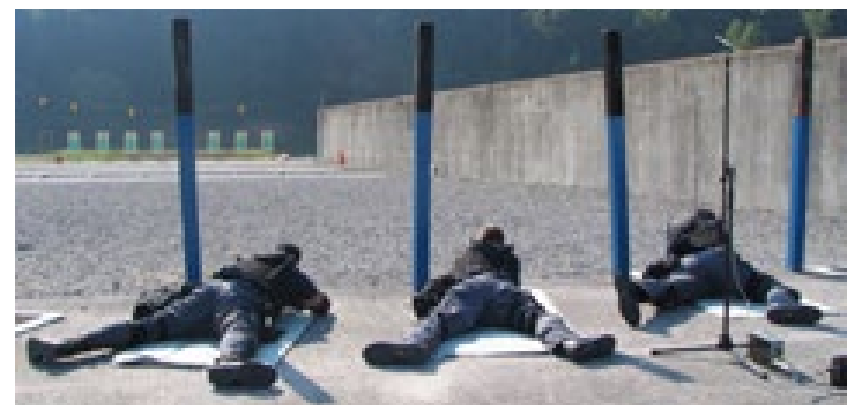

Figure 1. NIOSH exposure assessment of Federal law enforcement officers conducting a live-fire training exercise

\section{Recommendations}

Workers and shooters at outdoor firing ranges should take the following steps to protect themselves [NIOSH 2003, 2009, 2011]:

- Attend training, follow safe work practices, and participate in health monitoring programs.

- Report symptoms to your employer and get medical attention when needed:

- Common health effects of lead poisoning in adults include reproductive effects, nausea, diarrhea, vomiting, poor appetite, weight loss, anemia, fatigue, hyperactivity, headaches, stomach pain, and kidney problems.

- Exposure to high noise levels can cause hearing loss, tinnitus (ringing in the ear), stress, high blood pressure, fatigue, and gastro-intestinal problems.

- If you suspect you have had high lead exposure, even if you show no symptoms, get your BLL tested.

Practice good hygiene:

- Wash hands and face with soap and water or clean them with lead decontamination wipes after shooting, handling spent cartridge cases, or cleaning weapons, especially before eating, drinking, or smoking. Wipes for cleaning skin without water are commercially available and should be used if access to soap and water is limited [NIOSH 2009].

- Change clothes before leaving the range and wash clothes separately from other family clothing.

Use personal protective equipment (PPE):

- Wear double hearing protection (earplugs and earmuffs) and eye protection when shooting.

- Wear a brimmed cap and tight-fitting clothes for protection against hot shells and ejected casings if the range's shooting stations are in very close proximity.

- Wear properly-fitted respirators and full protective outer clothing for maintenance activities that involve close contact with lead dust or spent bullets.

- Wear gloves and eye protection when using chemicals to clean firearms.

Employers should take the following steps to protect workers and shooters at firing ranges:

- Consider providing non-lead bullets and non-lead primers (often referred to as "green" or non-toxic" ammunition) [NIOSH 2011].

- If state law permits, consider providing noise suppressors for gun barrels [NIOSH 2011].

- Establish effective engineering and administrative controls:

- Apply appropriate noise control measures, such as sound transmission barriers (i.e., walls, earthen berms), and absorptive materials such as acoustical treatments 
and natural vegetative (i.e., plants, trees, grass) buffers to limit noise in nearby areas [MN DNR 2003].

- If possible, use non-porous materials, coatings, or plastic covers on all contact surfaces to make them easier to clean.

- Limit the length of time that workers and shooters use the firing range: rotate assignments and provide quiet, clean, break areas.

- If you operate a range with ballistic or overhead baffles and wall structures, consider using fans behind the shooters and pointed down-range in order to provide sufficient air movement away from the shooters.

- Routinely clean the range using proper techniques and disposal methods. Do not use dry sweeping, wiping, or dusting. Use wet cleaning and HEPA vacuums only [NIOSH2011].

- Consider installing wind speed and direction meters.

- Post range safety rules and provide authority to range masters to enforce them.

- Provide workers and shooters with training and information about hazards:

- Inform workers and shooters about the importance of hygiene in reducing potential lead exposures, post warning signs, and provide convenient washing facilities to encourage frequent hand washing.

- Prohibit eating, smoking, chewing gum, or tobacco use in areas potentially contaminated with lead.

- Inform pregnant workers and shooters about possible risks to the fetus.

- Ensure that workers are aware of symptoms that may indicate a health problem.

- Tell workers about participating in medical surveillance programs and getting their BLLs tested, even if they don't show symptoms.

- Review OSHA requirements for medical monitoring for lead (29 CFR 1910.1025(j)) and noise (29 CFR 1910.95(d)(e)(g)(h)).

- For best medical and lead management practices, consult the Association of Occupational and Environmental Clinics [Kosnett et al. 2007].

- To reduce lead contamination at your range, consult the EPA's Best Management Practices for Lead at Outdoor Shooting Ranges [EPA 2001].

- Establish a hearing conservation program [NIOSH 2011].

- Provide workers with protective equipment:

- Provide and encourage the use of double hearing protection devices (earplugs and earmuffs) along with hygiene and cleaning kits.
- Provide skin protection, eye protection, and NIOSHapproved respirators ${ }^{\dagger}$ for workers who clean lead-contaminated areas.

- Provide knee or full body pads to limit transfer of lead to clothing.

\section{References}

CFR. Code of Federal regulations. Washington, DC: U.S. Government Printing Office, Office of the Federal Register.

DHHS [2010]. Healthy people 2020. Occupational Safety and Health Objective 7. Washington, DC: U.S. Department of Health and Human Services.

DOJ [2012]. Federal law enforcement officers, 2008. Washington, DC: U.S. Department of Justice, Office of Justice Programs [http://www. bjs.gov/content/pub/pdf/fleo08.pdf].

DOJ [2011]. Census of state and local law enforcement agencies, 2008. Washington, DC: U.S. Department of Justice, Office of Justice Programs [http://bjs.ojp.usdoj.gov/content/pub/pdf/csllea08.pdf].

EPA [2001]. Best management practices for lead at outdoor shooting ranges. Washington, DC: U.S. Environmental Protection Agency [www.epa.gov/region2/waste/leadshot].

Goldberg RL, Hicks AM, O’Leary LM, London S [1991]. Lead exposure at uncovered outdoor firing ranges. J Occup Med 33(6):718-719.

Kosnett MJ, Wedeen RP, Rothenberg SJ, Hipkins KL, Materna BL, Schwartz BS, Hu H, Woolf A [2007]. Recommendations for medical management of adult lead exposure. Environ Health Perspect 115(3): 463-471.

Mancuso JD, McCoy J, Pelka B, Kahn PJ, Gaydos JC [2008]. The challenge of controlling lead and silica exposures from firing ranges in a special operations force. Military Medicine 173(2):182-186.

MN DNR [2003]. Outdoor shooting ranges: best practices. St Paul, MN: State of Minnesota Department of Natural Resources.

NIOSH [1998]. Criteria for a recommended standard: occupational exposure to noise. DHHS (NIOSH) Publication No. 98-126 [http:// www.cdc.gov/niosh/docs/98-126/].

NIOSH [2003]. Health Hazard Evaluation report: Fort Collins Police Services-Colorado. By Tubbs RL, Murphy WJ. NIOSH HETA No. 2002-0131-2898 [http://www.cdc.gov/niosh/hhe/reports/pdfs/20020131-2898.pdf].

NIOSH [2009]. Preventing occupational exposures to lead and noise at indoor firing ranges. By Kardous C, et al. DHHS (NIOSH) Publication No. 2009-136 [http://www.cdc.gov/niosh/docs/2009-136/default.html]. NIOSH [2011]. Health Hazard Evaluation report: evaluating noise and lead exposures at an outdoor firing range-California. By Chen L, Brueck SE. NIOSH HETA No. 2011-0069-3140 [http://www.cdc. gov/niosh/hhe/reports/pdfs/2011-0069-3140.pdf].

NSSF [2010]. Modern sports rifle owners are most active shooters. Newton, CT: National Shooting Sports Foundation, Inc. [http://www. nssf.org/newsroom/releases/2010/041910.cfm].

Tripathi RK, Sherertz PC, Llewellyn GC, Armstrong CW [1991]. Lead exposure in outdoor firing range instructors. Am J Public Health 81(6):753-5.

\section{Acknowledgments}

This document was prepared by Chucri A. Kardous and Susan Afanuh, National Institute for Occupational Safety and Health.

${ }^{\dagger}$ A written respiratory protection program should be developed and implemented that meets the requirements of the OSHA respiratory protection standard [29 CFR 1910.134]. 
DEPARTMENT OF HEALTH AND HUMAN SERVICES

Centers for Disease Control and Prevention

National Institute for Occupational Safety and Health

4676 Columbia Parkway

Cincinnati, OH 45226-1998

Official Business

Penalty for Private Use $\$ 300$

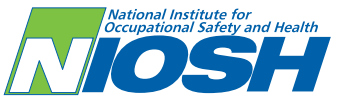

\section{For more information}

More information about firing ranges and NIOSH HHEs on firing ranges can be found on the NIOSH firing range topic page:

http://www.cdc.gov/niosh/topics/ranges/

General information about noise and lead exposures can be found on these NIOSH topic pages:

http://www.cdc.gov/niosh/topics/noise http://www.cdc.gov/niosh/topics/lead/

To obtain information about other occupational safety and health topics, contact NIOSH:

Telephone: 1-800-CDC-INFO (1-800-232-4636)

TTY: 1-888-232-6348 - E-mail: cdcinfo@cdc.gov

or visit the NIOSH Web site at www.cdc.gov/niosh

For a monthly update on news at NIOSH, subscribe to NIOSH eNews by visiting www.cdc.gov/niosh/eNews.

Reducing Exposure to Lead and Noise at Outdoor Firing Ranges
Mention of any company or product does not constitute endorsement by NIOSH. In addition, citations to Web sites external to - NIOSH do not constitute NIOSH endorsement of the sponsoring organizations or their programs or products. Furthermore, NIOSH is not responsible for the content of these Web sites.

This document is in the public domain and may be freely copied or reprinted. NIOSH encourages all readers of the Workplace Solutions to make them available to all interested employers and workers.

As part of the Centers for Disease Control and Prevention, NIOSH is the Federal agency responsible for conducting research and making recommendations to prevent work-related illness and injuries. All Workplace Solutions are based on research studies that show how worker exposures to hazardous agents or activities can be significantly reduced.

DHHS (NIOSH) Publication No. 2013-104 